\title{
Propionate of a microbiota metabolite induces cell apoptosis and cell cycle arrest in lung cancer
}

\author{
KWANGKHO KIM $^{1 *}$, OHMAN KWON ${ }^{1 *}$, TAE YOUNG RYU ${ }^{1}$, CHO-ROK JUNG ${ }^{1,2}$, JANGHWAN KIM ${ }^{1,2}$, \\ JEONG-KI MIN ${ }^{1,2}$, DAE-SOO KIM ${ }^{1,2}$, MI-YOUNG SON ${ }^{1,2}$ and HYUN-SOO CHO ${ }^{1,2}$ \\ ${ }^{1}$ Stem Cell Research Center, Korea Research Institute of Bioscience and Biotechnology, Daejeon 34141; \\ ${ }^{2}$ Department of Functional Genomics, Korea University of Science and Technology, Daejeon 34113, Republic of Korea
}

Received December 19, 2018; Accepted May 17, 2019

DOI: $10.3892 / \mathrm{mmr} .2019 .10431$

\begin{abstract}
Short-chain fatty acids (SCFAs; butyrate, propionate and acetate) are metabolites derived from the gut microbiota via dietary fiber fermentation. In colon cancer, treatment with SCFAs, mainly butyrate and propionate, suppresses cell proliferation, migration and invasion. Furthermore, although sodium butyrate is known to induce cell apoptosis in lung cancer, the anticancer effects of sodium propionate (SP) on lung cancer are not well understood. In the present study, SP treatment induced cell cycle arrest, especially in the G2/M phase, and cell apoptosis in the H1299 and H1703 lung cancer cell lines. As determined by reverse transcription-quantitative PCR and western blotting, Survivin and p21 expression levels were significantly affected by SP treatment, suggesting that SP treatment suppressed cell proliferation in these lung cancer cell lines. Thus, it was proposed that the SP-mediated regulation of Survivin and p21 in lung cancer may be applicable to lung cancer therapy.
\end{abstract}

\section{Introduction}

The microbiota and microbiome-derived metabolites in the colon have been recognized as an alternative therapy for colon cancer treatment (1). The microbiota in the colon produce short-chain fatty acids (SCFAs; butyrate, propionate and acetate) via dietary fiber fermentation to maintain human health (2). Several in vivo and in vitro studies have reported that SCFAs, mainly butyrate, exert anticancer effects, such

Correspondence to: Dr Hyun-Soo Cho or Dr Mi-Young Son, Stem Cell Research Center, Korea Research Institute of Bioscience and Biotechnology, 125 Gwahak-ro, Yuseong, Daejeon 34141, Republic of Korea

E-mail: chohs@kribb.re.kr

E-mail: myson@kribb.re.kr

*Contributed equally

Key words: lung cancer, propionate, cell cycle, apoptosis, survivin, $\mathrm{p} 21$ as suppressing cell growth, migration and invasion, on colon cancer $(3,4)$. Recently, sodium butyrate treatment was shown to upregulate miR-3935 expression, which prohibited the proliferation and migration of A549 cells (5). However, despite studies on the roles of SCFAs in the colon, the anticancer effects of SCFAs, especially propionate, on lung cancer are not well understood. Therefore, the present study examined the anticancer effects and molecular mechanism of sodium propionate (SP) using lung cancer cell lines.

Survivin, an antiapoptotic protein, is overexpressed in several types of cancer, and knockdown of Survivin induces cell apoptosis by increasing Bad and Bax expression and inducing G2/M arrest (6). Additionally, in an in vivo xenograft model of KRAS-mutant lung adenocarcinoma, Survivin knockdown and trametinib treatment induced cell death (7). Moreover, in hepatocellular carcinoma cells, treatment with ATB-263, a novel Bcl-2 inhibitor, and silencing of Survivin induced cell apoptosis; these results implied that Survivin knockdown is an important method to overcome the hurdle of drug resistance in cancer therapy (8), and the development of a method for silencing Survivin is urgently needed.

Therefore, in the present study, cell cycle arrest and apoptosis were investigated in lung cancer cell lines treated with SP, and downregulated Survivin expression and upregulated p21 expression was found. Based on the results of this study, the novel utilization of propionate for lung cancer treatment is proposed, due to its anticancer effects.

\section{Materials and methods}

Cell culture and reagents. $\mathrm{H} 1299$ and $\mathrm{H} 1703$ are non-small cell lung carcinoma (NSCLC) cell lines. NSCLC accounts for $\sim 85 \%$ of all lung cancer cases and is more insensitive to chemotherapy than small cell lung carcinoma (SCLC). As NSCLCs are a main lung cancer type and are difficult to treat, NSCLC cell lines were selected to assess the activity of propionate. The human lung cancer cell lines H1299 and H1703 were purchased from the Korean Cell Line Bank and cultured in RPMI supplemented with $10 \%$ FBS and $1 \%$ penicillin/streptomycin in a humidified atmosphere with $5 \% \mathrm{CO}_{2}$ at $37^{\circ} \mathrm{C}$. The normal human lung cell line MRC5 was purchased from the Korean Cell Line Bank and cultured in MEM supplemented with $10 \%$ FBS and $1 \%$ penicillin/streptomycin in a humidi- 
fied atmosphere with $5 \% \mathrm{CO}_{2}$ at $37^{\circ} \mathrm{C}$. SP (cat. no. P5436) was purchased from Sigma-Aldrich; Merck KGaA. H1299 and H1703 cells were treated with $10 \mathrm{mM}$ SP for $48 \mathrm{~h}$. Distilled water was used for the control treatments (9).

Cell viability assay. For crystal violet staining (10,11), cells treated with $0 \mathrm{mM}$ (DW), and $10 \mathrm{mM}$ SP for $48 \mathrm{~h}$ were washed twice with PBS and fixed with cold $100 \%$ methanol for 5 min at $20^{\circ} \mathrm{C}$. After being washed twice with PBS, the cells were stained with a $0.1 \%$ crystal violet solution (cat. no. C0775; Sigma Aldrich; Merck KGaA) for $5 \mathrm{~min}$ at room temperature. The cells were then washed five times with distilled water and observed under a light microscope (magnification, x100; OLYMPUS 1X71; Olympus Corporation).

Fluorescence-activated cell sorting (FACS) analysis. After treatment with SP for $48 \mathrm{~h}$, the cells were collected and incubated with Muse Annexin V \& Dead Cell Reagent (Merck $\mathrm{KGaA}$; cat. no. MCH100105) for $20 \mathrm{~min}$ at room temperature. After incubation, approximately $5 \times 10^{3}$ cells were analyzed with a Muse cell analyzer (Merck KGaA) (12). FACS analysis with propidium iodide staining was performed. For cell cycle analysis after treatment with SP, cells treated with SP for $48 \mathrm{~h}$ were fixed with $70 \%$ ethanol and incubated with Muse ${ }^{\circledR}$ Cell Cycle Assay reagent (Merck KGaA; cat. no. MCH1001060) for $30 \mathrm{~min}$ at room temperature, according to the manufacturer's instructions. To measure the activity of caspase 3/7, the Muse Caspase-3/7 kit (Merck KGaA; cat. no. MCH100108) was used. According to the user's guide, cells treated with SP for $48 \mathrm{~h}$ were treated with Muse Caspase-3/7 working solution and incubated for $30 \mathrm{~min}$ in a $37^{\circ} \mathrm{C}$ incubator with $5 \% \mathrm{CO}_{2}$. After incubation, $\sim 5 \times 10^{3}$ cells were analyzed with a Muse cell analyzer (EMD Millipore). The FACS results were analyzed using Muse 1.5 Analysis software (Merck KGaA).

Reverse transcription-quantitative $(R T-q) P C R$. Total RNA was isolated from the indicated cell lines using a Qiagen RNeasy Mini kit (Qiagen, Inc.), according to the manufacturer's instructions. RNA aliquots of $1 \mu \mathrm{g}$ were then reverse transcribed using the iScript ${ }^{\mathrm{TM}}$ cDNA synthesis kit (Bio-Rad Laboratories, Inc.), according to standard protocols: $5 \mathrm{~min}$ at $25^{\circ} \mathrm{C}, 20 \mathrm{~min}$ at $46^{\circ} \mathrm{C}$ and $1 \mathrm{~min}$ at $95^{\circ} \mathrm{C}$. qPCRs were performed using the AriaMx Real-Time PCR instrument (Agilent Technologies, Inc.), according to the manufacturer's instructions. qPCR was performed on cDNA samples using Brilliant III Ultra-Fast SYBR ${ }^{\circledR}$ Green qPCR Master Mix (Agilent Technologies, Inc.), and the signal was detected by the AriaMx Real-time PCR System (Agilent Technologies). The thermocycling conditions were as follows: $95^{\circ} \mathrm{C}$ for $3 \mathrm{~min}$, followed by 40 cycles of $95^{\circ} \mathrm{C}$ for $5 \mathrm{sec}$ and $55^{\circ} \mathrm{C}$ for $10 \mathrm{sec}$. The fluorescence threshold value was calculated using Agilent Aria 1.6 software (Agilent Technologies, Inc.) $(13,14)$. Using the Agilent Aria 1.6 software, $\Delta \mathrm{Cq}$ values were calculated and normalized to $\beta$-actin (ACTB; https://www.agilent.com/cs/library/applications/application-fod-cannabis_5994-0430en-agilent.pdf). The following PCR primers were used: E2F transcription factor (E2F)1 (forward, 5'-GGACCTTCGTAGCATTGCAG-3' and reverse, 5'-CTGATCCCACCTACGGTCTC-3'), E2F2 (forward, 5'-AGGAGCTGAAGGAGCTGATG-3' and reverse, 5'-TCTTGTTGGCCTTGTCCTCA-3'), E2F4 (forward, 5'-CGG
GAGCAAGAACTAGACCA-3' and reverse, 5'-TCCTCATGA GTGACGTAGGC-3'), CDK4 (forward, 5'-ACAGCTACCAGA TGGCACTT-3' and reverse, 5'-GTCGGCTTCAGAGTTTCC AC-3'), cyclin A2 (CCNA2; forward, 5'-CATGGACCTTCA CCAGACCT-3' and reverse, 5'-AGTGTCTCTGGTGGGTTG AG-3'), cyclin B2 (CCNB2; forward, 5'-AGTTCCAGTTCA ACCCACCA-3' and reverse, 5'-GCAGAGCAAGGCATC AGAAA-3'), p21 (forward, 5'-CTTTGTCACCGAGAC ACCAC-3' and reverse, 5'-CAGGTCCACATGGTCTTCCT-3'), Survivin (forward, 5'-AGGACCACCGCATCTCTACAT-3' and reverse, 5'-AAGTCTGGCTCGTTCTCAGTG-3') and ACTB (forward, 5'-ACTCTTCCAGCCTTCCTTCC-3' and reverse, 5'-CAATGCCAGGGTACATGGTG-3').

Western blot analysis. Cells were washed once with PBS and then lysed in cold lysis buffer [50 mM Tris $\mathrm{HCl}(\mathrm{pH} 7.4)$, $150 \mathrm{mM} \mathrm{NaCl}, 1 \%$ Triton $\mathrm{X}-100,0.1 \%$ SDS, $1 \mathrm{mM}$ EDTA, $1 \mathrm{mM} \mathrm{Na} \mathrm{VO}_{4}, 1 \mathrm{mM} \mathrm{NaF}$ and $1 \mathrm{X}$ protease inhibitor cocktail]. Cell lysates were centrifuged at $14,000 \times \mathrm{g}$ for $15 \mathrm{~min}$ at $4^{\circ} \mathrm{C}$, boiled in $5 \mathrm{X}$ sample buffer, and subjected to protein determination (BSA; cat. no. 23208; Thermo Fisher Scientific, Inc.). Protein samples $(10 \mu \mathrm{g})$ were subjected to western blot analysis as follows: Nitrocellulose membranes (cat. no. 1620145; Bio-Rad Laboratories, Inc.), blocking reagent (5\% skim milk; $1 \mathrm{~h}$ at room temperature) and precast gels (4-20\% Mini-PROTEAN ${ }^{\circledR}$ TGX $^{\text {TM }}$; cat. no. 456 1094; Bio-Rad Laboratories, Inc.) were used with the indicated antibodies at a 1:1,000 dilution ratio $(15,16)$. Samples were stained with anti-Survivin (cat. no. 2803S), anti-poly (ADP-ribose) polymerase (PARP; cat. no. 9542S), and anti-Caspase 3 (cat. no. 9662S) antibodies from Cell Signaling Technology, Inc., and anti-p21 (cat. no. SC-6246) and anti-ACTB (cat. no. SC-47778) antibodies from Santa Cruz Biotechnology Inc. at $4^{\circ} \mathrm{C}$ (overnight). Secondary antibodies at a 1:5,000 dilution (rabbit, cat. no. SC-2357; mouse, cat. no. SC-2031; Santa Cruz Biotechnology, Inc.) were incubated at room temperature for $1 \mathrm{~h}$, and an ECL solution (cat. no. 170-5060; Bio-Rad Laboratories, Inc.) was used for visualization. The results were analyzed using ImageJ software (version 1.8.0; National Institutes of Health).

Statistical analysis. Results are expressed as the mean \pm SD of three independent experiments. Student's t-test was used to assess significance using Microsoft Excel 2013 (Microsoft Corporation). $\mathrm{P}<0.05$ was considered to indicate a statistically significant difference.

\section{Results}

SP suppresses the growth of lung cancer cell lines. To investigate the anticancer effect of SP against lung cancer, cell growth assays were performed on H1299 and H1703 cell lines after SP treatment. After $10 \mathrm{mM}$ SP treatment, cell growth was significantly lower than that after control treatment, as determined by crystal violet staining (Fig. 1). However, treatment of a normal lung cell line (MRC5) with SP had no effect on cell growth compared to that observed in the lung cancer cell lines, as determined by the cell growth assay (data not shown). Although several studies have recently shown that SCFAs, including propionate, suppress growth in colon cancer cell 

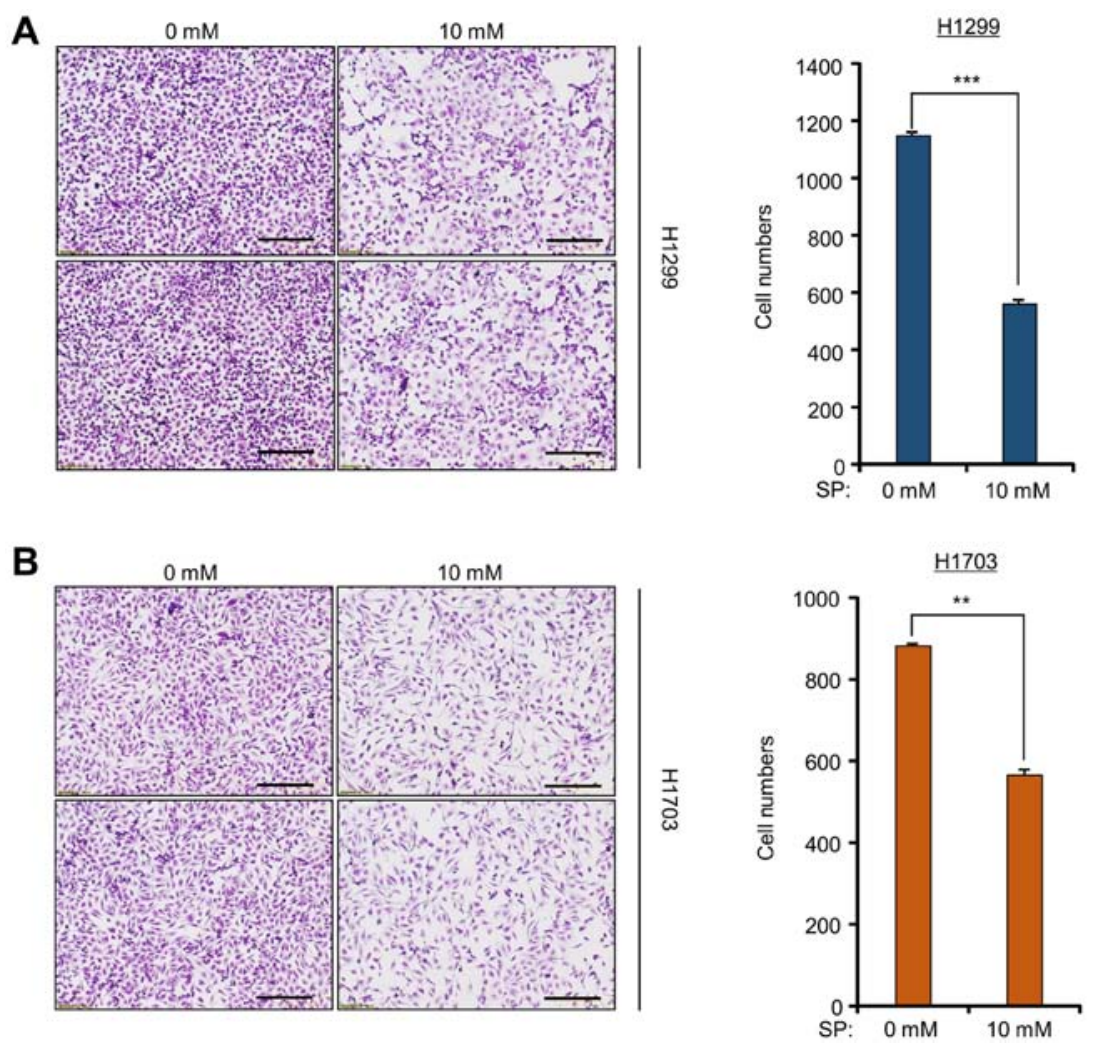

Figure 1. SP suppresses the proliferation of H1299 and H1703 cells. Cell growth assays were performed (crystal violet staining). After SP treatment (0 and $10 \mathrm{mM}$ ), (A) H1299 and (B) H1703 cells were fixed in 100\% methanol and stained with crystal violet solution. The cells were imaged with a microscope. Scale bar, $140 \mu \mathrm{m}$. P-values were calculated using Student's t-tests. ${ }^{* *} \mathrm{P}<0.01 ;{ }^{* * *} \mathrm{P}<0.001$. SP, sodium propionate.

lines (17-19), it was observed in the present study that SP also has anticancer effects against lung cancer cell lines. Thus, an alternative therapeutic method using SP is proposed for lung cancer treatment.

SP induces G2/M arrest in lung cancer cell lines. SCFA treatment initiates cell cycle arrest and apoptosis in colon cancer cell lines $(18,20)$. Thus, the present study also assessed the effects of SP on the cell cycle in lung cancer cell lines. To verify the relationship between the cell cycle and SP treatment in the H1299 and H1703 cell lines, FACS analysis with propidium iodide staining was performed. As shown in Fig. 2A and B, dose-dependent $\mathrm{G} 2 / \mathrm{M}$ arrest was clearly observed after treatment of the H1299 and H1703 cell lines with SP, implying that SP-induced G2/M arrest inhibited cell growth in these lung cancer cell lines.

Next, to evaluate the role of SP treatment at the molecular level, primers were designed for the amplification of various cell cycle-related genes (E2F1, E2F2, E2F4, CDK4, CCNA2, CCNB2, p21 and Survivin) (6,21-23). The RT-qPCR results clearly showed that the expression levels of the E2F family members, CDK4, CCNA2, CCNB2 and Survivin were significantly decreased after SP treatment in the H1299 and H1703 cell lines. Moreover, the expression of p21, a cyclin-dependent kinase inhibitor (22), was clearly induced by SP treatment in both lung cancer cell lines. In particular, G2/M arrest-related genes (CCNA2, CCNB2, Survivin and p21) were significantly reduced or induced in the SP-treated groups compared to those in the control groups (Fig. 2C). Thus, it may be concluded that SP treatment reduced the transcription of cell cycle-related genes, especially those related to the $\mathrm{G} 2 / \mathrm{M}$ phase, to inhibit the cell growth of lung cancer cell lines.

SP treatment induces the apoptosis of H1299 and H1703 cells. Li et al (6) reported that silencing Survivin expression by siRNA treatment resulted in cell apoptosis and G2/M arrest in the Heal and MCF7 cell lines. In addition, the upregulation of p21 expression induced cell apoptosis and cell cycle arrest (24). Thus, to confirm the regulation of Survivin and p21 expression by SP treatment in more detail, western blot analysis was performed with anti-Survivin and anti-p21 antibodies. After treatment with SP $(10 \mathrm{mM})$, the Survivin and p21 protein expression levels were significantly decreased and increased, respectively (Fig. 3A). Next, to determine whether SP-induced growth suppression was related to cell apoptosis, FACS analysis was performed using Annexin V. The proportions of cells in early and late apoptosis were greater in the SP treatment group than in the control group (Fig. 3B). Moreover, the induction of the apoptosis markers cleaved PARP and cleaved caspase 3 by SP treatment was investigated in the $\mathrm{H} 1299$ and $\mathrm{H} 1703$ cell lines, revealing that SP treatment induced cell apoptosis by controlling Survivin and p21 expression in these lung cancer cell lines (Fig. 4A). In addition, to confirm the western blotting results, FACS analysis was performed to measure the activity of caspase 3/7. As shown in Fig. 4B, the activity of caspase 3/7 was increased by SP treatment. Taken together, the present data show that SP treatment induced apoptosis and cell cycle arrest by regulating Survivin and p21 expression in lung cancer cell lines, similar to its effects on colon cancer; these molecular mechanism data provide useful information 
A
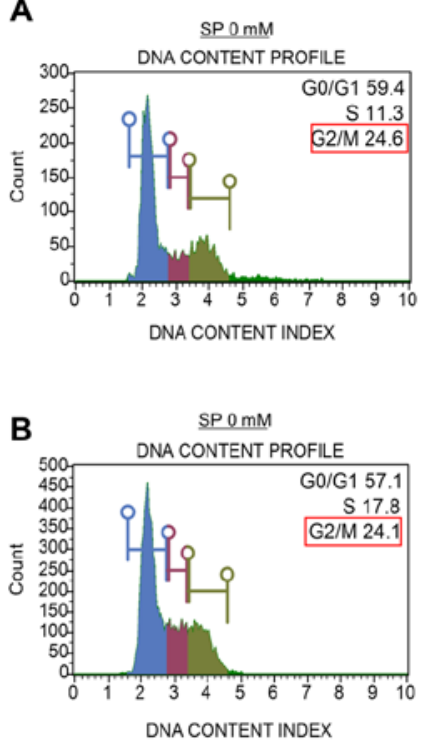

$\underline{S P} 10 \mathrm{mM}$

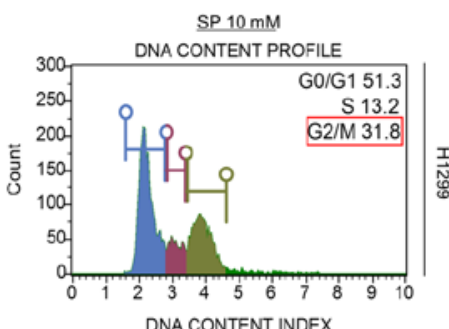

SP $10 \mathrm{mM}$

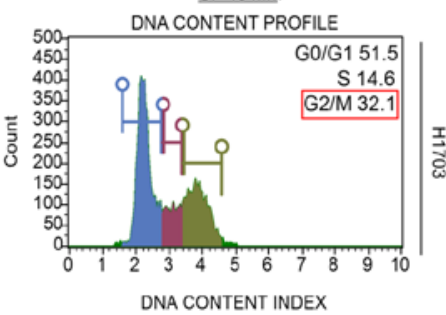

C
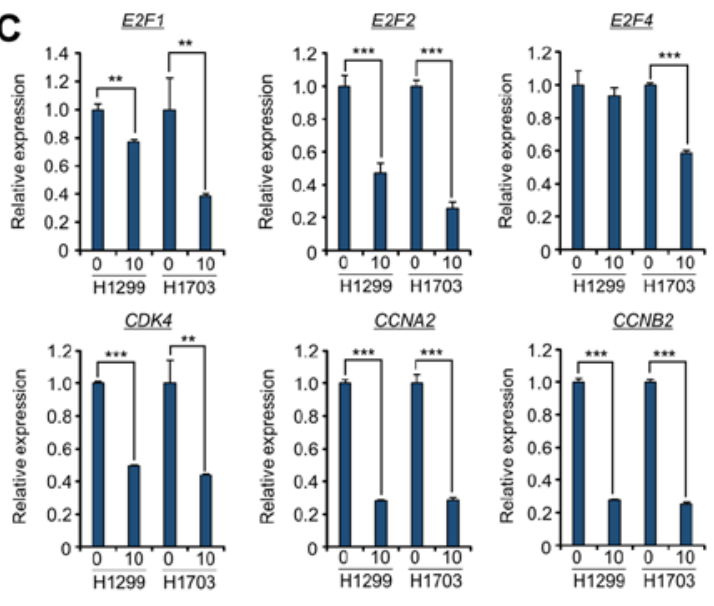
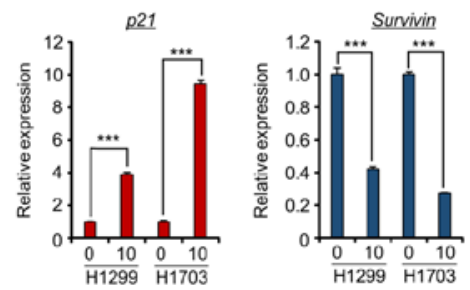

Figure 2. Cell cycle-related genes in lung cancer cell lines are regulated by SP treatment. FACS analysis using PI staining was performed after treatment of (A) H1299 and (B) H1703 cells with SP (0 and $10 \mathrm{mM}$ ). (C) Reverse transcription-quantitative PCR analysis of cell cycle-related genes after treatment with SP. P-values were calculated using Student's t-tests. ${ }^{* *} \mathrm{P}<0.01 ;{ }^{* * *} \mathrm{P}<0.001$. SP, sodium propionate; E2F, E2F transcription factor; CCNA2, cyclin A2; CCNB2, cyclin B2.
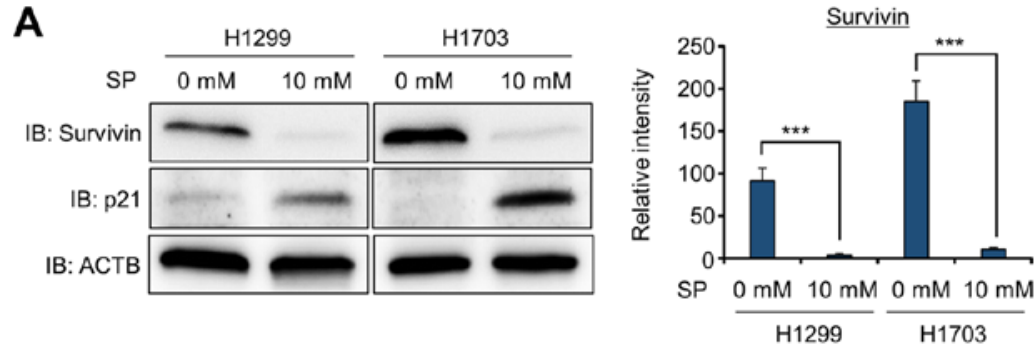

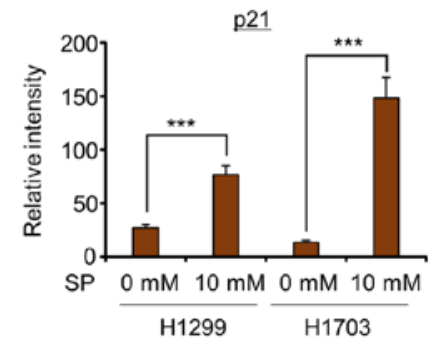

B
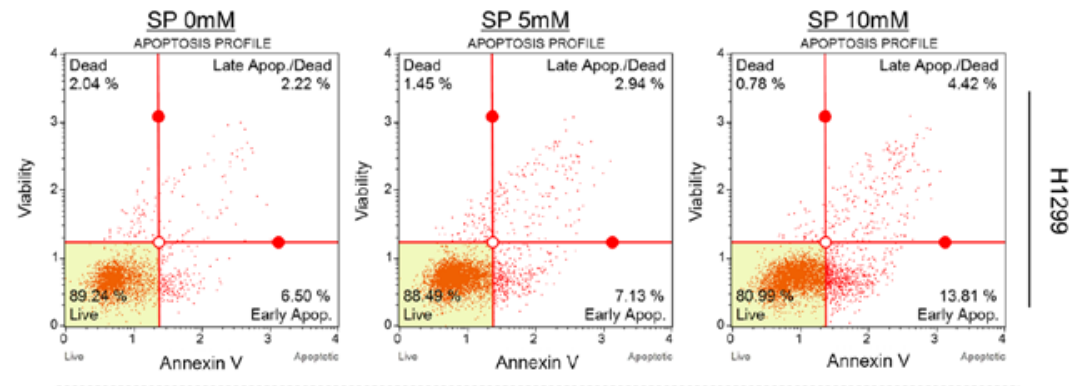

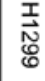
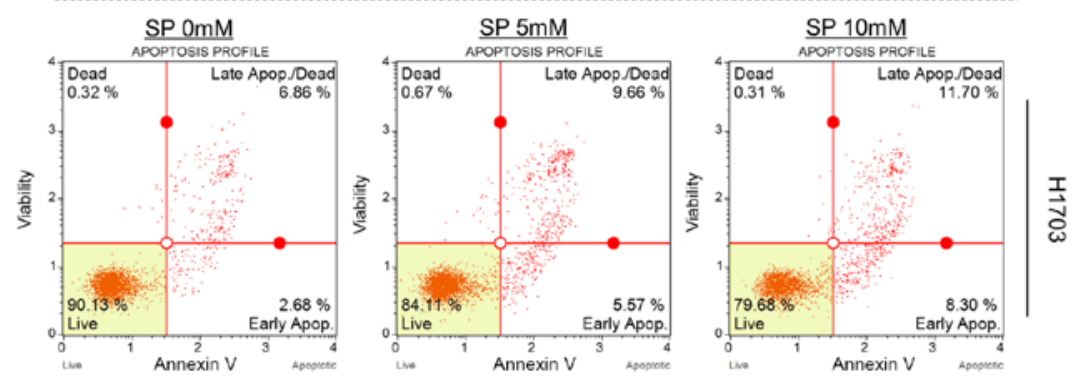

Figure 3. SP treatment induces cell apoptosis by regulating Survivin and p21 expression. (A) Western blot analysis after treatment with SP using anti-Survivin and anti-p21 antibodies. ACTB was used as the internal control (left panel), and the signal intensity corresponding to Survivin and p21 was quantified using ImageJ software (right panel). P-values were calculated using Student's t-tests. ${ }^{* * * *} \mathrm{P}<0.001$. (B) Fluorescence activated cell sorting analysis using Annexin V staining was performed after SP treatment. The lower right and upper right panels indicate early and late apoptosis, respectively. SP, sodium propionate; ACTB, $\beta$-actin. 
A

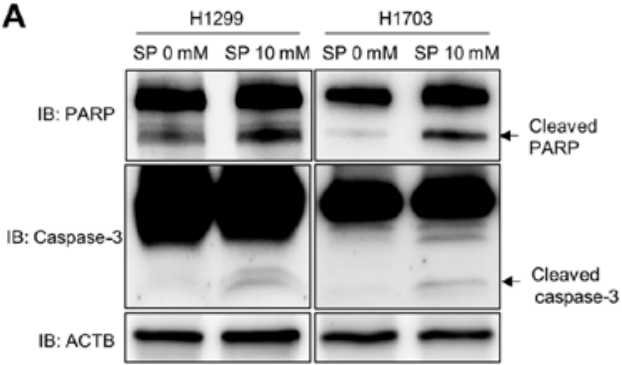

C

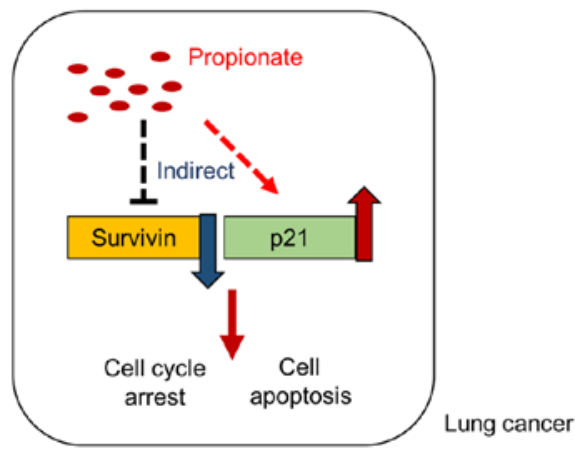

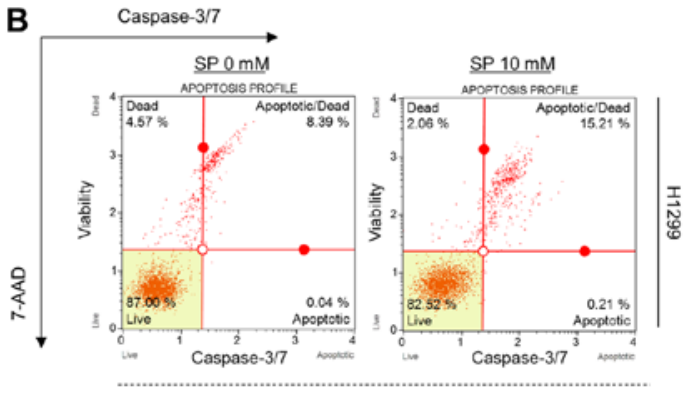

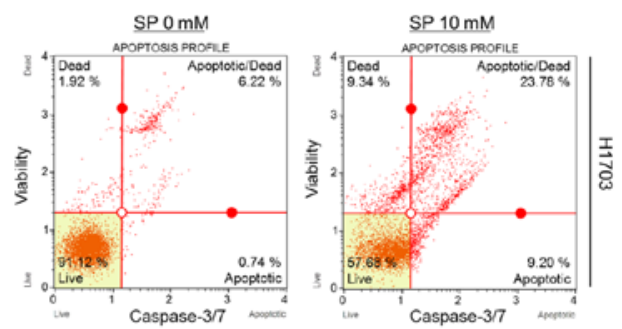

Figure 4. SP treatment induces cleaved PARP and caspase-3/7 activity in H1299 and H1703 cells. (A) Western blot analysis after SP treatment using anti-PARP and anti-caspase-3 antibodies. Actin (ACTB) was used as the internal control. (B) FACS analysis using the Muse Caspase-3/7 working solution was performed after SP treatment. The upper right panel indicates apoptotic and dead cell portions. (C) Schematic summary of the effects of SP on lung cancer. SP, sodium propionate; PARP, poly (ADP-ribose) polymerase; ACTB, $\beta$-actin; 7-AAD, 7-aminoactinomycin D.

on the potential role of the anticancer effector propionate in lung cancer treatment (Fig. 4C).

\section{Discussion}

SCFAs derived from the microbiome affect colon cancer proliferation by modulating histone hyperacetylation and dysregulating Bcl-2, Bax, p21 and proliferating cell nuclear antigen expression $(18,25)$. In addition, sodium butyrate can also suppress the proliferation of other cancer types, such as lung and prostate cancer, by regulating p21 expression $(26,27)$. However, as most studies on SCFAs have focused on butyrate, the functionality of propionate in lung cancer is not widely known. Therefore, the present study established a hypothesis regarding the relationship between lung cancer and propionate based on several previous studies (25-27), and provided novel functional information regarding the role of propionate in lung cancer treatment. To assess the function of propionate in lung cancer, it was necessary to choose between two types of propionate, SP and propionic acid (PA), because propionate cannot exist solely in nature. However, when PA is added to cell culture media, the acidic effects on cancer cells must be negated. Thus, to assess the anticancer activity of propionate, SP was selected, although its general use is as a mold inhibitor in baked goods.

SP inhibited lung cancer cell proliferation by inducing cell cycle arrest, especially in the G2/M phase. Moreover, to identify the relationship between cell cycle-related genes and SP treatment, RT-qPCR analysis was performed, and it was found that several cell cycle-related genes were up- or downregulated by SP treatment. Although downregulation of the E2F family and CDK4 was previously shown to be mainly involved in G1 arrest (21), the reduction rates of the E2F family and
CDK4 were broadly lower than those of CCNA2, CCNB2 and Survivin as determined by RT-qPCR analysis. Thus, it was hypothesized that in the lung cancer cell lines, SP treatment may affect the entire cell cycle machinery, particularly G2/M arrest, and that this regulation may suppress cell proliferation.

The anticancer drug epigallocatechin-3-gallate (EGCG) augments the anticancer effect of leptomycin B (LMB) treatment on lung cancer cells by upregulating p21 and downregulating Survivin. Although the clinical usage of EGCG is a subject of debate, combination therapy with LMB exerts a synergistic effect on lung cancer cell lines (28). In the present study, the induction of caspase $3 / 7$ activity and apoptosis by SP treatment was observed in lung cancer cell lines. Western blot analysis also showed that SP treatment increased cleaved PARP and caspase 3 expression by down- and upregulating Survivin and $\mathrm{p} 21$, respectively. Thus, the novel suggestion is proposed that SP may function as a sensitizer of LMB treatment and could be combined with LMB in lung cancer therapy. However, to translate this hypothesis to the clinic, the activity of SP must be evaluated in vivo, and an accurate mode-of-action study on propionate treatment for the regulation of Survivin and p21 expression is required.

In conclusion, although propionate treatment is known to suppress cell growth and induce apoptosis in colon cancer cell lines, the results of the present study suggested that it could also function as an anticancer drug for the treatment of lung cancer, by inducing cell apoptosis and cell cycle arrest by down- and upregulating Survivin and p21 expression, respectively. Therefore, although many hurdles must be cleared for SCFAs to be applicable in lung cancer treatment, the present results suggest that SCFAs derived from the microbiome and dietary therapy may help patients with lung cancer; however, in vivo studies are needed to validate the effectiveness of SP. 


\section{Acknowledgements}

Not applicable.

\section{Funding}

This study was supported by a grant from the National Research Foundation of Korea (NRF), funded by the Ministry of Science, ICT and Future Planning (grant no. NRF-2018M3A9H3023077).

\section{Availability of data and materials}

The datasets used and/or analyzed during the current study are available from the corresponding author on reasonable request.

\section{Authors' contributions}

MYS, DSK, JK and HSC were involved in the conception and design of the study. KK, OK and TYR were involved in the development of the methodology, and the analysis and interpretation of the data. CRJ, JK, JKM, DSK, MYS and HSC were involved in the writing, reviewing and/or revision of the manuscript. CRJ, JKM, JK and MYS were responsible for administrative, technical or material support. CRJ and JKM were involved in the design of the study,

\section{Ethics approval and consent to participate}

Not applicable.

\section{Patient consent for publication}

Not applicable.

\section{Competing interests}

The authors declare that they have no competing interests.

\section{References}

1. Rea D, Coppola G, Palma G, Barbieri A, Luciano A, Del Prete P, Rossetti $\mathrm{S}$, Berretta $\mathrm{M}$, Facchini $\mathrm{G}$, Perdonà $\mathrm{S}$, et al: Microbiota effects on cancer: From risks to therapies. Oncotarget 9: 17915-17927, 2018.

2. Tan J, McKenzie C, Potamitis M, Thorburn AN, Mackay CR and Macia L: The role of short-chain fatty acids in health and disease. Adv Immunol 121: 91-119, 2014.

3. Tian Y, Xu Q, Sun L, Ye Y and Ji G: Short-chain fatty acids administration is protective in colitis-associated colorectal cancer development. J Nutr Biochem 57: 103-109, 2018.

4. Wu X, Wu Y, He L, Wu L, Wang X and Liu Z: Effects of the intestinal microbial metabolite butyrate on the development of colorectal cancer. J Cancer 9: 2510-2517, 2018.

5. Xiao X, Cao Y and Chen H: Profiling and characterization of microRNAs responding to sodium butyrate treatment in A549 cells. J Cell Biochem 119: 3563-3573, 2018.

6. Li Y, Liu D, Zhou Y, Li Y, Xie J, Lee RJ, Cai Y and Teng L: Silencing of Survivin Expression Leads to Reduced Proliferation and Cell Cycle Arrest in Cancer Cells. J Cancer 6: 1187-1194, 2015.

7. Sumi T, Hirai S, Yamaguchi M, Tanaka Y, Tada M, Yamada G, Hasegawa T, Miyagi Y, Niki T, Watanabe A, et al: Survivin knockdown induces senescence in TTF 1-expressing, KRAS-mutant lung adenocarcinomas. Int J Oncol 53: 33-46, 2018.

8. Zhao X, Ogunwobi OO and Liu C: Survivin inhibition is critical for Bcl-2 inhibitor-induced apoptosis in hepatocellular carcinoma cells. PLoS One 6: e21980, 2011.
9. Kim K, Son MY, Jung CR, Kim DS and Cho HS: EHMT2 is a metastasis regulator in breast cancer. Biochem Biophys Res Commun 496: 758-762, 2018.

10. Kim SK, Kim K, Ryu JW, Ryu TY, Lim JH, Oh JH, Min JK, Jung CR, Hamamoto R, Son MY, et al: The novel prognostic marker, EHMT2, is involved in cell proliferation via HSPD1 regulation in breast cancer. Int J Oncol 54: 65-76, 2018.

11. Ryu TY, Kim K, Kim SK, Oh JH, Min JK, Jung CR, Son MY, Kim DS and Cho HS: SETDB1 regulates SMAD7 expression for breast cancer metastasis. BMB Rep 52: 139-144, 2019.

12. Ryu TY, Kim K, Son MY, Min JK, Kim J, Han TS, Kim DS and Cho HS: Downregulation of PRMT1, a histone arginine methyltransferase, by sodium propionate induces cell apoptosis in colon cancer. Oncol Rep 41: 1691-1699, 2019.

13. Kim DS, Ryu JW, Son MY, Oh JH, Chung KS, Lee S, Lee JJ, Ahn $\mathrm{JH}$, Min JS, Ahn J, et al: A liver-specific gene expression panel predicts the differentiation status of in vitro hepatocyte models. Hepatology 66: 1662-1674, 2017.

14. Son MY, Jung CR, Kim DS and Cho HS: Comparative in silico profiling of epigenetic modifiers in human tissues. Mol Biol Rep 45: 309-314, 2018.

15. Jung KB, Lee H, Son YS, Lee MO, Kim YD, Oh SJ, Kwon O, Cho S, Cho HS, Kim DS, et al: Interleukin-2 induces the in vitro maturation of human pluripotent stem cell-derived intestinal organoids. Nat Commun 9: 3039, 2018.

16. Ryu JW, Kim SK, Son MY, Jeon SJ, Oh JH, Lim JH, Cho S, Jung CR, Hamamoto R, Kim DS, et al: Novel prognostic marker PRMT1 regulates cell growth via downregulation of CDKN1A in HCC. Oncotarget 8: 115444-115455, 2017.

17. Davie JR: Inhibition of histone deacetylase activity by butyrate. J Nutr 133 (Suppl 7): 2485S-2493S, 2003.

18. Hinnebusch BF, Meng S, Wu JT, Archer SY and Hodin RA: The effects of short-chain fatty acids on human colon cancer cell phenotype are associated with histone hyperacetylation. J Nutr 132: 1012-1017, 2002.

19. Ooi CC, Good NM, Williams DB, Lewanowitsch T, Cosgrove LJ, Lockett TJ and Head RJ: Structure-activity relationship of butyrate analogues on apoptosis, proliferation and histone deacetylase activity in HCT-116 human colorectal cancer cells. Clin Exp Pharmacol Physiol 37: 905-911, 2010.

20. Heerdt BG, Houston MA and Augenlicht LH: Short-chain fatty acid-initiated cell cycle arrest and apoptosis of colonic epithelial cells is linked to mitochondrial function. Cell Growth Differ 8: 523-532, 1997.

21. Bertoli C, Skotheim JM and de Bruin RA: Control of cell cycle transcription during G1 and S phases. Nat Rev Mol Cell Biol 14: 518-528, 2013.

22. El-Deiry WS: p21(WAF1) Mediates Cell-Cycle Inhibition, Relevant to Cancer Suppression and Therapy. Cancer Res 76: 5189-5191, 2016.

23. Park AM, Tsunoda I and Yoshie O: Heat shock protein 27 promotes cell cycle progression by down-regulating E2F transcription factor 4 and retinoblastoma family protein p130. J Biol Chem 293: 15815-15826, 2018.

24. Karimian A, Ahmadi Y and Yousefi B: Multiple functions of p21 in cell cycle, apoptosis and transcriptional regulation after DNA damage. DNA Repair (Amst) 42: 63-71, 2016.

25. Emenaker NJ, Calaf GM, Cox D, Basson MD and Qureshi N: Short-chain fatty acids inhibit invasive human colon cancer by modulating uPA, TIMP-1, TIMP-2, mutant p53, Bcl-2, Bax, p21 and PCNA protein expression in an in vitro cell culture model. J Nutr 131 (Suppl 11): 3041S-3046S, 2001.

26. Rephaeli A, Blank-Porat D, Tarasenko N, Entin-Meer M, Levovich I, Cutts SM, Phillips DR, Malik Z and Nudelman A: In vivo and in vitro antitumor activity of butyroyloxymethyl-diethyl phosphate (AN-7), a histone deacetylase inhibitor, in human prostate cancer. Int J Cancer 116: 226-235, 2005.

27. Edmond V, Brambilla C, Brambilla E, Gazzeri S and Eymin B: SRSF2 is required for sodium butyrate-mediated p21(WAF1) induction and premature senescence in human lung carcinoma cell lines. Cell Cycle 10: 1968-1977, 2011.

28. Cromie MM and Gao W: Epigallocatechin-3-gallate enhances the therapeutic effects of leptomycin B on human lung cancer a549 cells. Oxid Med Cell Longev 2015: 217304, 2015.

(i) (-) This work is licensed under a Creative Commons Attribution-NonCommercial-NoDerivatives 4.0 International (CC BY-NC-ND 4.0) License. 